\title{
PROMOTING LANGUAGE LEARNERS' CROSS-CULTURAL AWARENESS THROUGH COMPARATIVE ANALYSES OF ASIAN FOLKTALES ${ }^{i}$
}

\author{
Soe Marlar Lwin \\ (smarlar.lwin@nie.edu.sg) \\ National Institute of Education, Nanyang Technological University \\ 1 Nanyang Walk, Singapore
}

\begin{abstract}
With the global spread, the English language has become a lingua franca and a component of basic education in many Asian countries, making Asia one of the regions in the world with the largest number of English speakers. However, due to the rich cultural diversities of Asian societies, using English as a lingua franca in Asia implies that speakers need to develop not only communicative competence but intercultural communicative competence, so as to ensure successful communication among people from different Asian societies. Given that successful intercultural communication requires the speakers' appreciation of their cultural diversities, while celebrating certain similarities, promoting learners' cross-cultural awareness has become one of the important objectives of English language teaching in Asia. In this paper, I will draw on some sample analyses of Asian folktales which have been translated into English to (i) identify and explore the features of narrative structures and contents which can be seen as transcultural and others which can be highlighted as culture-specific, and (ii) discuss how such comparative analyses of narrative structures and contents in Asian folktales can be used to promote the cross-cultural awareness of English language learners in Asia. Implications for the socio-cultural-based English language teaching are offered.
\end{abstract}

Keywords: Asian folktales, narrative structures and contents, English as a lingua franca, language learners, cross-cultural awareness

DOI: http://dx.doi.org/10.15639/teflinjournal.v27i2/166-181 
With more Asian societies becoming increasingly cosmopolitan in the $21 \mathrm{st}$ century, the education systems in several Asian countries have continued to reform themselves toward 21st century learning (Lee, Hung \& Teh, 2014; Teo, 2015). Among these education goals for 21 st century learning, one of the aspects which have been emphasized for the 21 st century competencies is for learners to develop global and cross-cultural awareness (e.g., See the Singapore Ministry of Education framework of 21st century competencies and desired outcome). Specifically, 21st century learners need broader worldviews and the ability to communicate and work with people from diverse cultural backgrounds, with different ideas and perspectives. In this context, it is imperative that the teaching and learning of English, which has been a component of basic education in many Asian countries, recognize such a need to promote learners' cross-cultural awareness. With the global spread, the English language has been a lingua franca in many Asian countries, making Asia one of the regions in the world with the largest number of English speakers. However, due to the rich cultural diversities of Asian societies, using English as a lingua franca in Asia implies that speakers need to develop not only communicative competence but intercultural communicative competence so as to ensure successful communication among people from different Asian societies and beyond.

Intercultural competence can be explained as realization of one's own culture locatedness, that is, the ability to contextualize one's own cultural practices, assumptions, beliefs, etc. and the ability to successfully deal with other cultures (Luciana, 2005). In her intercultural framework for oral communication, Luciana (2005) has identified attitudes of curiosity and openness as the prime catalyst for developing knowledge of self and others, and has stressed that such knowledge is not automatically grasped by learners and should, therefore, be made explicit to them. Similarly, Chen and Starosta (1999) define intercultural communicative competence as "the ability to effectively and appropriately execute communication behaviours that negotiate each other's cultural identity or identities in a culturally diverse environment" (p. 28). These definitions imply that development of learners' intercultural communicative competence can be facilitated by promoting their critical understanding of own culture as well as of others'.

In the field of language teaching, with the advent of communicative approaches there have been many studies on developing learners' communicative competence, following the introduction of Canale and Swain's (1980) framework for teaching and testing communicative competence. Nevertheless, only 
few studies have made attempts at defining and describing intercultural communicative competence (e.g., Alptekin, 2002; Byram, 1997, 2009; Chen \& Starosta, 1999; Luciana, 2005). Studies which specifically explore methods or ways to promote learners' cross-cultural awareness are even fewer. In this paper, I will draw on some sample analyses of Asian folktales which have been translated into English to (i) identify and explore the features of narrative structures and contents which can be seen as transcultural and others which can be highlighted as culture-specific, and (ii) discuss how such comparative analyses of narrative structures and contents in Asian folktales can be used to promote the cross-cultural awareness of English language learners in Asia. Given that successful intercultural communication requires the speakers' appreciation of their cultural diversities, while celebrating certain similarities, promoting learners' cross-cultural awareness should be one of the important objectives of English language teaching in Asia.

Folktales are traditional stories that have been passed on by words of mouth before writing systems were developed. They include fables (i.e., tales with animals as the main characters and an explicit moral lesson), fairy tales (i.e., tales with some magical elements), myths (i.e., tales which are considered sacred), among many other sub-types (Taylor, 2000). Being part of folk literature, folktales typically address themes and issues that are profound for all humanity and significant for all ages. It has been claimed that "[a] knowledge of folk literature is of prime importance for a fuller understanding of human behaviour and culture" (Eugenio, 1995, p. 1). At the same time, the "folk literature of a people is a very valuable part of its cultural heritage, for in it one finds the roots of the culture of that people (Eugenio, 1995, p. 1). Specifically in the Asian context, efforts have been made to preserve and disseminate the rich folk literature including folktales of Asia. For example, volumes which include the most popular examples of tales from different Asian countries having been collected and translated into English have been published to promote the understanding and friendship among the people of Asian countries (e.g., ASEAN folk literature: An anthology). Taking advantage of the availability of such collections of folktales from different countries in Asia, I will first conduct a comparative analysis of Asian folktales to identify and explore features of narrative structures and contents which can be seen as transcultural (or) culture-specific, before exploring the pedagogical implications for promoting learners' crosscultural awareness. 


\section{METHOD}

Folktales are typically regarded as the simplest form of narrative, and tales from various cultures have been analyzed in terms of their structures and contents. The structural analysis of tales (i.e., a description of the tale according to the sequence of events which make up the storyline of the tale) can be claimed to have begun with Propp's (1968) Morphology of the folktale. Following Propp's ground-breaking morphological classification of Russian tales, there have been studies of structural typology of folktales from different cultures. However, most of these studies were done on a collection of tales from a particular culture or a particular type of tales. Hence, development in this line of inquiry has not been cumulative. A comparative analysis of narrative structures and contents in folktales of different cultures, especially those from neighboring nations such as countries in Asia, is an area that warrants further research. Neighboring countries, each with its own unique culture, are likely to have some influence on each other's culture and share certain common cultural features. Thus it would be interesting to explore and identify what elements in their folktales can be claimed to be transcultural and what elements are culturespecific by comparing them from the standpoint of narrative structures and contents. While any similarities across tales of different Asian countries will highlight possibly transcultural elements, any distinctiveness will highlight uniqueness of a particular culture. Understanding of such similarities and differences is in turn likely to facilitate appreciation of cultural diversities in Asia.

For a comparative analysis of folktales, I will begin with the extraction of all functional events making up the storyline of each of the tales. Propp (1968) posits that functional events, as an act of a character defined from the point of view of its significance for the course of the action, can be extracted as basic components of the tale. Similarly, Toolan (2001) suggests that labelling of events and states in terms of Propp's functional events is one of the methods to analyze the basic story structure; given that an event, bringing a change of state, is the most fundamental requirement in narrative. As for the distribution of narrative roles by the characters in each tale, a major character carrying out the functional events in the plot will broadly be identified as the Protagonist. When a tale has more than one major character, they will be identified as Protagonist A, B, C, etc. Moreover, following Propp (1968), a character who prepares and/or provides Protagonist with the magical agent will be identified as the Donor. A character who assists, rescues, solves and/or transfigures the Pro- 
tagonist will be identified as the Guide or Helper. Following the classification of characters in each tale to the appropriate narrative roles, the functional events constituting a storyline will be identified.

For example, in the Myanmar folktale The Golden Crow (Maung Htin Aung, 1976), there are two protagonists, one of whom behaves according to certain specific rules, and is rewarded. The other breaks these rules and is punished. The four narrative roles in the tale are distributed as follows.

$\begin{array}{ll}\text { Good-natured girl: } & \text { Protagonist A } \\ \text { Bad-tempered girl: } & \text { Protagonist B } \\ \text { Golden Crow: } & \text { Donor } \\ \text { Tray of paddy: } & \text { Guide }\end{array}$

The events making up the narrative structure or story line of this tale are extracted as follows.

Move 1 Protagonist A is introduced.

Long ago there lived an old widow who was very poor. She had a daughter who was pretty and good-natured.

Event 1 Guide leads Protagonist A to Donor.

One day while the good-natured girl was watching over a tray of paddy which was being dried in the sun, a crow with gold feathers came and ate up the entire tray of paddy.

Event 2 Protagonist A meets Donor.

To pay for the paddy, the Golden Crow asked the good-natured girl to come to the big tamarind tree outside the village at sunset. When the girl went there, she saw a little house of gold at the top and the Golden Crow looked out of a window of the little golden house.

Event 3 Donor sets Protagonist A tasks/tests.

The crow asked the girl if she wanted the golden ladder, the silver ladder or the brass ladder to come up.

The crow asked the girl if she wanted the gold dish, the silver dish or the brass dish to eat the food from.

The crow asked the girl if she wanted a big box, a medium-sized box, and a small box to give to her mother.

Event 4 Protagonist A performs the tasks/tests successfully. The girl chose the brass ladder for the first question. The girl chose the brass dish for the second question. 
The girl chose the little box for the last question saying that paddy the crow ate was not much.

Event 5 Protagonist A is rewarded.

When the girl reached home, she gave the little box to her mother. Together they opened it and found in the box a hundred priceless rubies.

Move 2 Protagonist B is introduced.

There was another widow in the village and she also had a daughter who, however, was greedy and bad-tempered.

Event 1 Guide leads Protagonist B to Donor.

While the bad-tempered girl was watching over a tray of paddy which was being dried in the sun, a crow with gold feathers came and ate up all the paddy.

Event 2 Protagonist B meets Donor.

To pay for the paddy, the Golden Crow asked the girl to come to the big tamarind tree outside the village at sunset. When the girl went there, she saw a little house of gold at the top and the Golden Crow looked out of a window of the little golden house.

Event 3 Donor sets Protagonist B tasks/tests.

The crow asked the girl if she wanted the golden ladder, the silver ladder or the brass ladder to come up.

The crow asked the girl if she wanted the gold dish, the silver dish or the brass dish to eat the food from.

The crow asked the girl if she wanted a big box, a medium-sized box, and a small box to give to her mother.

Event $4 \quad$ Protagonist B fails.

The girl chose the golden ladder for the first question.

The girl chose the gold dish for the second question.

The girl chose the big box for the last question and left without remembering to thank the crow.

Event 5 Protagonist B is punished.

When the girl reached home, she gave the little box to her mother. Together they opened it and found a big snake coiled inside the big box. 
The above sequence of events in this type of tales can be summarized as the reward/punishment model or structural pattern:

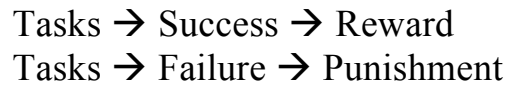

For an illustration of contrastive analyses of Asian folktales, I will focus on the following two structural patterns or models which have been identified in my earlier studies of Myanmar folktales (Lwin, 2010) as a basis:

- reward/ punishment

- interdiction/violation

\section{FINDINGS AND DISCUSSION}

\section{Reward/Punishment}

As explained above, the narrative structure of a folktale with the reward/punishment model can be summarized as:

\section{Tasks $\rightarrow$ Success $\rightarrow$ Reward Tasks $\rightarrow$ Failure $\rightarrow$ Punishment}

The parallel sets of contrasting narratives in this type of tales shows how good actions are rewarded and evil actions are punished. Interestingly, this reward/ punishment model or the contrastive narrative structure identified in the analysis of Myanmar folktales is also found in tales from other Asian cultures. For example, Grayson (2002) in his study of Korean folktales has also found that there is a large set of Korean folktales which are composed of parallel sets of contrasting narratives showing how good actions are rewarded and evil actions punished. It is claimed that the contrastive narrative structure can be found in tales throughout East Asia. However, Grayson distinguishes Korean tales from similar tales in China and Japan as an illustration of the Confucian concept of moral suasion, in addition to the common theme of rewards and punishments. The narrative roles and structures of a Korean reward/ punishment folktale, The Story of Hungbu and Nolbu, can be identified as follows: 
Kind-hearted younger brother Hungbu: Protagonist A Greedy older brother Nolbu : Protagonist B

Swallow: Donor

Snake: Guide

Move 1:

Events:

Move 2:

Events:
The younger brother is introduced.

The good actions of the younger brother

The younger brother's reward

The older brother is introduced.

The evil actions of the older brother

The punishment of the older brother

Similar to the Myanmar folktale The Golden Crow, the Korean folktale The Story of Hungbu and Nolbu is also composed of two equal narrative sections or acts/moves, each consisting of two scenes which balance each other with parallel narrative content but come to a different conclusion, or dénouement. The first act or Move 1 gives a didactic moral point by showing the good motives and their consequences, while the second act or Move 2, which is formally identical to the first, contrasts the narrative content of the previous act to emphasis on the punishment which arises from bad motives.

Interestingly, a similar parallel set of contrasting narratives on how good actions are rewarded and evil actions are punished is also found in The King of the Mosquitoes - a folktale of Brunei Darussalam (Eugenio, 1995). The four narrative roles in the tale are distributed as follows.

$\begin{array}{ll}\text { Good-natured younger sister: } & \text { Protagonist A } \\ \text { Bad-tempered older sister: } & \text { Protagonist B } \\ \text { King of the mosquitoes: } & \text { Donor } \\ \text { Mosquitoes and nipah leaves: } & \text { Guide }\end{array}$

Similar to the Myanmar folktale The Golden Crow, and the Korean folktale The Story of Hungbu and Nolbu, a folktale of Brunei Darussalam The King of the Mosquitoes is also made up of two narrative sections or acts/moves, each consisting of the mother (a widow) asking the two girls (younger and older sisters) to gather nipah leaves for their house roof. While they were gathering nipah leaves, a few mosquitoes came and bit them. To express their anger, the 
sisters (each in turn) asked the mosquitoes to bring them to their king. The king of mosquitoes set the tests/tasks - asking them to cook their own food using worms as rice, blood as water, animal bones as firewood and an old skull as the cooking pot. The younger sister reacted calmly and humbly and was rewarded with a box of gold and diamonds. The elder sister failed the test, and the box given to her contained poisonous snakes.

A comparison among the folktales with the reward/punishment narrative structure from Myanmar, Korea and Brunei Darussalam reveals that different cultures may offer different tasks or tests for the protagonists; nevertheless, the underlying message of what is morally or ethically right, what is wrong and what can be their consequences is proved to be the same. Although a comparison of narrative content in the three tales reveals certain culture-specific elements, for example, the choice of Protagonists (widows and their daughters versus the elder and younger brothers), Donor (a golden crow versus a swallow versus the king of the mosquitoes), and Guide (a tray of paddy versus a snake versus mosquitoes and nipah leaves); the nature of rewards and punishments and the social purpose of teaching morally significant issues on what is right and its consequences are common in tales from all the three cultures. Moreover, such morally significant issues are foregrounded in all the three tales when they are placed in parallel against what is wrong and its consequences.

\section{Interdiction/Violation}

In this model, the violation of an interdiction or a contract between the two protagonists will lead to a movement from equilibrium to disequilibrium. The preservation of an interdiction or a contract between the two protagonists, on the other hand, will lead to the continuation of equilibrium. Thus the structure of those tales with Interdiction/ violation model can be summarized as

Interdiction $\rightarrow$ Preservation $\rightarrow$ Equilibrium maintained (or) Interdiction $\rightarrow$ Violation $\rightarrow$ Disequilibrium

In a Myanmar folktale The Great King Eats Chaff (Maung Htin Aung, 1976) as an example, the narrative roles and functional events making up the story line of the tale can be outlined as follows.

Protagonist A: The King

Protagonist B: The Attendant 
Protagonists are introduced.

The great king, with only one attendant, went incognito for a stroll in his city. He stopped to watch an old woman pounding paddy.

Event 1

Event 2

Event 3

Event 4

Event 5
Equilibrium between the protagonists.

The chaff which the old woman threw away after her pounding smelt very sweet, and the king was seized with an overmastering desire to eat it. He walked on for a few yards, and then ordered his attendant to go back and bring some of the chaff as he wanted to eat it. The attendant was shocked and protested that it was a disgraceful thing for a great king to eat chaff, which was food fit only for animals. But the king insisted. So the chaff had to be fetched, and the king ate it with relish.

An interdiction is made between the protagonists. Then the great king said to the attendant, "If you tell about this to anyone, off goes your head."

Protagonist B is tested.

When the attendant reached home he was seized with an itch to tell. He tried to eat, he tried to sleep, and he tried to sing, but to no purpose, the itch to tell remained. "If only I could whisper it out," he thought. Two or three days passed, and the attendant became ill and haggard, but the itch to tell still tortured him.

Interaction is violated. In the end, he went to the forest and, putting his head in the hollow of a big tree, whisper fervently, "The great king eats chaff. The great king eats chaff. The great king eats chaff."

Discovery of violation and the end of equilibrium. Many months later, as the big palace drum which announced the hours to the people becoming too old to remain serviceable for long, a new drum had to be ordered. The drum-makers went to the forest and cut down a big tree, to use its wood for the new drum. It happened that the tree they cut down was the very tree in the hollow of which the attendant had whispered out his secret. At last the new drum was ready. It was a beautiful thing. With great ceremony, and before a huge crowd of people, the new drum was installed; but when the drum was beaten, it did not say "boom, boom" as is usual with all drums, but said instead, "The great king eats chaff. The great king eats chaff." 
A similar narrative structure is also found in an Indian folktale BabbanHajjaam (BabbanHajjaam and Other Stories, 1979).

Narrative roles:

Protagonist A: Nawab Anwar (the ruler)

Protagonist B: BabbanHajjaam (the court barber)

An interdiction was made to keep the secret between the ruler Nawab Anwar and the court barber BabbanHajjaam, after BabbanHajjaam found out that Nawab Anwar was born with donkey's ears. BabbanHajjaam was seized with an itch to tell. In the end, he disclosed the secret to a hole dug near a deodar tree. When the tree was cut and made into musical instruments, the instruments revealed the secret at a recital. Similar to the Myanmar folktale The Great King Eats Chaff, the narrative structure of the Indian tale BabbanHajjaam can be summarized as:

$$
\text { Interdiction } \rightarrow \text { Violation } \rightarrow \text { Disequilibrium }
$$

A comparison between the two common structural patterns identified in the analysis of folktales of Myanmar and those folktales from other Asian cultures shows that despite certain culture-specific narrative contents, tales with similar social purposes (e.g., a didactic moral purpose) exhibit similar structural patterns. Such findings suggest that certain structural patterns are used commonly (if not universally) by various cultures for similar social purpose of storytelling. At the same time, the findings also imply that although different cultures may share the same structural pattern, the narrative contents of a tale (e.g., elements taking up the narrative roles) remain to be culture-specific.

\section{Pedagogical Implications: Promoting Learners' Cross-cultural Awareness}

It is often claimed that in most Asian cultures, folktales have been preserved for generations not only as a reflection of a particular culture but also as a means of instilling certain concepts in the society (Eugenio, 1995; Grayson, 2002). Understanding their similarities and differences (as shown in the above comparative analyses of some sample folktales from Myanmar, Korea, Brunei Darussalam and India) point to the possibilities of using such 
Asian folktales having been translated into English for promoting English language learners' cross-cultural awareness.

According to Bean (1999), the characteristic of universality or similarity of the fundamental event sequence in folktales from various cultures makes these tales "one of the most accessible vehicles for language learning" (p. 58). Familiar themes of honesty, kindness, jealousy, greed or other moral issues and familiar narrative structures such as the reward/punishment and interdiction/violation models in these tales can also motivate learners to listen or read with confidence (Taylor, 2000). In other words, familiarity with the underlying narrative structure and messages in a tale allows learners to use more cognitive space to pay attention to the language features. This in turn tends to facilitate their understanding of how specific vocabulary and grammatical patterns of English can be used to realize meanings which are familiar to them. Above all, folktales can be used as a pedagogical springboard to help learners develop skills in using the language to make critical or imaginative responses, and to explore language and culture simultaneously (Bean, 1999; Taylor, 2000). Tales with familiar themes or similar types of characters and events from other cultures can motivate learners to make comparisons, highlight similarities and differences, provide critical responses and justify opinions.

To illustrate, in the Myanmar folktale, through the kind actions and modest choices made by Protagonist A and the ways rewards were given for her contentment, the tale appears to be instilling the concept of contentment, a virtue particularly valued in Theravada Buddhism and the Burmese culture. Conversely, through the inhospitable actions and greedy choices made by Protagonist B and the punishment she received for her greed, the tale exposes the negative association of greed. In the teaching of Theravada Buddhism, greed is an element, along with anger and delusion, which is believed to be the root of immoral kamma (a Pali word meaning action). Accordingly, greed is an element that one needs to eradicate in the quest to attain nirvana (i.e., the state of being free from suffering) in Theravada Buddhism, the religion of the majority of Burmese people. In similar ways, the example of the Korean folk tales shows how the kind actions are rewarded and the malicious ones are punished; this illustrates how the cultural norms of social assistance are (re)affirmed by the tale and how seriously the violations of cultural norms are treated. However, it is claimed that through the portrayal of how the kind and virtuous younger brother whose generous actions and kind life is rewarded while the greed and maliciousness of the older brother is severely punished, the 
tale's purpose is not simply to show good is rewarded and evil punished (Grayson, 2002). The tale also reflects certain Confucian values, specifically the social relationships between the elder and younger brothers, which have been embedded in Korean society.

Similar comparisons can be made between the Myanmar folktale The Golden Crow and the folktale of Brunei Darussalam The King of the Mosquitoes. In the Myanmar folktale the two mothers (the widows) asked their respective daughter to watch a tray of paddy which was being dried in the sun. In the folktale of Brunei Darussalam, which has a similar narrative structure, the mother (a widow) asked her two daughters (younger and older sisters) to gather nipah leaves for their house roof. After having learners read the two tales, teachers might pose a series of questions as follows:

- Why do you think "a tray of paddy" was featured in the Myanmar tale? Why was it not "a loaf of bread"?

- Why do you think "nipah leaves" was featured in the tale from Brunei Darussalam?

- Why do you think the crow was chosen to be the bird that came and ate up the paddy?

- What do you think gold and its color (as in "gold feather" "gold ladder" and "gold plate") symbolize for the people and culture in which this tale was originated?

- Why do you think the worms, blood, animal bones and old skull were featured as ingredients for cooking in the test set for the two sisters by the King of Mosquitoes in the tale from Brunei Darussalam?

Comparing the Myanmar folktale The Great King Eats Chaff and the Indian folktale BabbanHajjaam, teachers can ask questions such as:

- Why do you think chaff was featured in the tale from Myanmar?

- Why do you think a barber was featured in the tale from India?

- How important is keeping an interdiction set by the King/the Ruler in a particular culture?

- In your opinion, how fair was the interdiction made between the King/the Ruler and the attendant/court barber? 
Learners from different cultures tend to have different beliefs, attitudes and experiences about humor, wits and wisdom, and thus are likely to respond differently to the interdiction and preservation/violation made in such tales.

In sum, teachers can facilitate learners in carefully examining the cultural assumptions present in folktale of different countries, and help them explore and learn how these cultural assumptions match or differ in tales from various cultures. The aim of the above sample questions is to help learners recognize the close relationship between language and culture. Language, as a system for organizing the experience of people, emphasizes whatever is prevalent or important to the culture of the people. For example, the paddy and the crow in a Myanmar folktale represent the staple food of the Myanmar people and a common type of birds found in that country respectively. Even though a folktale from another culture may share the same reward/punishment storyline with The Golden Crow, a comparison between the two tales will reveal certain culture-specific narrative contents in each. By having learners discuss and share their responses to these similarities and differences using the target language - English, teachers can use folktales to provide opportunities for learners to develop skills in using the target language to make critical responses (e.g. to questions on why a particular type of food, bird and color was chosen to be featured in the tale) and imaginative responses (e.g. to questions on what if the other types of food, bird and color were to replace those featured in the tale). When done in class, folktales can serve as a springboard for such task-based talk among learners, supporting the socio-cultural-based English language teaching and learning.

\section{CONCLUSIONS AND SUGGESTIONS}

According to Taylor (2000), folktales fit well with communicative approaches that focus on teaching language for communicating meaning. When folktales are used in language classes, the cultural elements of folktales also help to bridge common ground between cultures and at the same time bring out differences between them (Taylor, 2000). That is to say, folktales are useful for developing in the learners what Luciana (2005) calls attitudes of curiosity and openness - which is the prime catalyst for developing intercultural competence. Through a comparative analysis of folktales from the learners' culture and those from other Asian cultures, and an understanding of similarities and differences among them in terms of narrative structures and contents, learners can 
develop not only a critical understanding of their own culture but also an awareness of the rich cultural diversities of Asian societies. Such cross-cultural awareness can then be developed into the ability to effectively and appropriately communicate and work with people from diverse cultural backgrounds in Asia, using English as a lingua franca in the $21^{\text {st }}$ century.

\section{REFERENCES}

Alptekin, C. (2002). Towards intercultural communicative competence in ELT. ELT Journal, 56(1), 57-64.

BabbanHajjaam and Other Stories (1979). Laughing Lion Stories Series. Faridabad, India: Thomson.

Bean, M. (1999). The role of traditional stories in language teaching and learning. In M. R. MacDonald (Ed.), Traditional storytelling today: An international sourcebook, (pp. 548-551). London: Fitzroy Dearborn.

Byram, M. (1997). Teaching and assessing intercultural communicative competence. Clevedon: Multilingual Matters.

Byram, M. (2009). Intercultural competence in foreign languages: The intercultural speaker and the pedagogy of foreign language education. In D. K. Deardorff (Ed.), The SAGE handbook of intercultural competence (pp. 321-332). London: Sage.

Canale, M., \& Swain, M. (1980). Theoretical bases of communicative approaches to second language teaching and testing. Applied Linguistics, 1(1), 1-47.

Chen, G. M., \& Starosta, W. J. (1999). A review of the concept of intercultural awareness. Human Communication, 2, 27-54.

Eugenio, D. L. (1995). (Ed.) ASEAN folk literature: An anthology. Manila: ASEAN Committee on Culture and Information.

Grayson, J. H. (2002). The Hungbu and Nolbu tale type: A Korean double contrastive narrative structure, Folklore 113(1), 51- 69. 
Lee, S. S., Hung, D., \& Teh, L. W. (2014). Toward $21^{\text {st }}$ century learning: An analysis of top performing Asian education systems' reforms. Asia-Pacific Education Researchers, 23(4), 779-781.

Luciana. (2005). Developing learner oral communication: Intercultural perspective. In J. Foley (Ed.). New dimensions in the teaching of oral communication, (pp. 20-32). Singapore: SEAMEO Regional Language Centre.

Lwin, S. M. (2010). Narrative structures in Burmese folk tales. Amherst, NY: Cambria Press.

Maung Htin Aung (1976). Folk tales of Burma. New Delhi: Sterling Publishers.

Propp, V. (1968). Morphology of the folk tales. The American Folklore Society and Indiana University

Singapore Ministry of Education. Framework for 21st Century Competencies and Student Outcomes. Retrieved from https://www.moe.gov.sg/ education/education-system/21st-century-competencies

Taylor, E. K. (2000). Using folktales. Cambridge: Cambridge University Press.

Teo, P. (2015). Educating for the $21^{\text {st }}$ century: The Singapore experience. In B. Spolsky \& K. Sung (Eds.) Secondary school English education in Asia: From policy to practice (pp. 65-82). Abingdon: Routledge.

Toolan, M. J. (2001). Narrative: A critical linguistic introduction ( $2^{\text {nd }}$ ed.). New York, NY: Routledge.

\footnotetext{
i This paper was presented as a keynote speech at the $4^{\text {th }}$ Language, Society and Culture in Asian Contexts (LSCAC) 2016 in Malang, Indonesia in May 2016.
} 